\title{
Torulaspora delbrueckii Yeast Strains for Small-scale Chenin blanc and Pinotage Vinifications
}

\author{
V. van Breda ${ }^{1,2}$, N.P. Jolly ${ }^{1 *}$, M. Booyse ${ }^{3}$, J. van $\mathrm{Wyk}^{2}$ \\ (1) ARC Infruitec-Nietvoorbij, Private Bag X5026, Stellenbosch, 7599, South Africa \\ (2) Cape Peninsula University of Technology, PO Box 1906, Bellville, 7535, South Africa \\ (3) ARC Biometry, Private Bag X5026, Stellenbosch 7600, South Africa
}

Submitted for publication: October 2017

Accepted for publication: March 2018

Keywords: Non-Saccharomyces yeast, Saccharomyces cerevisiae, small-scale vinifications, fermentation, Torulaspora delbrueckii, Chenin blanc, Pinotage

\begin{abstract}
Nine Torulaspora delbrueckii yeast strains, a commercial $T$. delbrueckii strain and a commercial Saccharomyces cerevisiae yeast strain were used in the production of small-scale Chenin blanc and Pinotage vinifications. The fermentations were carried out at $15^{\circ} \mathrm{C}$ and $24^{\circ} \mathrm{C}$ respectively. Four $\mathrm{T}$. delbrueckii yeasts were used as single inoculants, while the remainder were inoculated sequentially. The commercial $S$. cerevisiae yeast strains were added at zero, 24 and 48 hours after the $T$. delbrueckii strain. The wines were evaluated chemically and sensorially and the data was analysed statistically. The results for the white wine vinification trial showed that two $T$. delbrueckii treatments could produce novel wines, either on their own or as a component of co-inoculated fermentations. These compared well with, and even exceeded, the quality of wine produced by the $S$. cerevisiae reference treatment regarding chemical composition and overall sensory quality. One $T$. delbrueckii strain showed its robustness by being re-isolated from the yeast lees at the end of fermentation. The red wine vinifications were less conclusive, and no distinctive T. delbrueckii "fingerprint" was observed in the chemical and sensory data, neither was a pattern observed regarding the different inoculation times.
\end{abstract}

\section{INTRODUCTION}

Modern wine production relies on selected pure yeast strains with desired qualities as starter cultures (Lema et al., 1996; Egli et al., 1998; Pretorius, 2000). This gives the winemaker better control over the fermentation process, and a predictable outcome (Degré, 1993; Henick-Kling et al., 1998). The alternative method, of spontaneous fermentation, in which the fermentation is driven by the yeast naturally present in grape must, carries a higher risk of an undesirable outcome. The yeasts responsible for spontaneous fermentations come either directly from the grapes, or are transferred from the processing equipment (Pretorius, 2000). Despite the high risks and unpredictability associated with spontaneous fermentations, many winemakers prefer this method. This is partially due to the desirable effects on wine flavour, complexity and distinct vintage variability caused by the many non-Saccharomyces yeasts present on the grapes and in the crushed grape must (Lambrechts \& Pretorius, 2000; Romano et al., 2003; Jolly et al., 2014; Padilla et al., 2016). As much as $90 \%$ to $100 \%$ of the total population of indigenous yeasts are non-Saccharomyces yeasts. These yeasts are capable of initiating alcoholic fermentation (Fleet
\& Heard, 1993), and the predominant genera can include Hanseniaspora (Kloeckera), Dekkera (Brettanomyces), Cryptoccocus, Metschnikowia (Candida), Debaryomyces, Lachancea (Kluyveromyces), Pichia (Candida), Rhodotorula, Saccharomycodes, Schizosaccharomyces, Torulaspora (Candida), Lindnera (Williopsis) and Zygosaccharomyces (Erten \& Campbell, 2001; Holm Hansen et al., 2001; Van Keulen et al., 2003; Deák, 2007; Ciani \& Comitini, 2011; Kurtzman et al., 2011; Jolly et al., 2014; Alonso et al., 2015; Renault et al., 2016; Benito et al., 2017; Domizio et al., 2017).

In contrast to earlier studies, which showed that non-Saccharomyces yeasts only dominated during the early stages of wine fermentation, with $S$. cerevisiae completing the fermentation (Amerine \& Kunkee, 1969), more recent studies have shown that non-Saccharomyces yeasts survive at significant levels and for longer periods, thereby influencing the chemical and sensory profiles of the wine (Moreno et al., 1991; Ciani \& Maccarelli, 1998; Granchi et al., 1998; Farías et al., 2003; Fleet, 2003; Combina et al., 2005; Ciani \& Comitini, 2011; Jolly et al., 2014). It has

*Corresponding author: Email address: jollyn@arc.agric.za

Acknowledgments: The authors wish to thank Winetech, the Agricultural Research Council Infruitec-Nietvoorbij and the Cape Peninsula University of Technology for financial support, and the ARC Infruitec-Nietvoorbij Post-Harvest and Wine Technology Division for the use of their laboratories and facilities, as well as the Microbiology team for technical assistance 
further been shown that some non-Saccharomyces species greatly improve the quality and sensorial properties of wine (Loureiro \& Malfeito-Ferreira, 2003; Hornsey, 2007; Jolly et al., 2003a; 2003b; Benito et al., 2016; Padilla et al., 2016; Renault et al., 2016; Benito et al., 2017).

Metabolic, chemical and sensory profile studies of non-Saccharomyces yeast fermentations have shown that $T$. delbrueckii species in particular make a positive contribution toward the flavour of alcoholic beverages (Ciani \& Picciotti, 1995; Ciani \& Maccarelli, 1998; Jolly et al., 2003a; Van Breda et al., 2013; Belda et al., 2015; Loira et al., 2015; Renault et al., 2015; Chen \& Liu, 2016; Renault et al., 2016; Ngqumba et al., 2017). This was further demonstrated in a study conducted by Hernández-Orte et al. (2008), in which wines produced with T. delbrueckii had high concentrations of aliphatic lactones and ethyl dihydrocinnamate, imparting sensory notes such as "dried fruit" and "coconut" to the wine. Compounds such as linalool, $\beta$-phenylethanol and $\beta$-phenylethyl acetate, which impart "rose" notes, were also detected. Studies conducted by Bely et al. (2008) showed that T. delbrueckii had high fermentation purity by producing very low volatile acidity (acetic acid and ethyl acetate) and acetaldehyde levels. In addition, this species also produced low quantities of undesirable compounds such as acetoin.

In recent years, selected non-Saccharomyces wine yeasts have been commercially dried, or have been included as part of mixed active dried starter cultures with $S$. cerevisiae (Comitini et al., 2011; Jolly et al., 2014; Azzolini et al., 2015). This gives the winemaker the beneficial effects of spontaneous fermentation without the accompanying risks (Romano et al., 2003; Ciani et al., 2006).

The aim of this study was to investigate the potential of nine $T$. delbrueckii yeast isolates used singly or co-inoculated with $S$. cerevisiae for the production of small-scale white and red vinifications to produce wine with lower alcohol concentrations, while at the same time maintaining or improving the wine quality.

\section{MATERIALS AND METHODS}

\section{Yeast strains}

Nine T. delbrueckii strains (654, M2/1, 301, 704, 206, $\mathrm{M} 2 / 15, \mathrm{M} 2 / 19, \mathrm{M} 2 / 27$ and M2B/27) from the ARC InfruitecNietvoorbij culture collection, one isolate $(\mathrm{TdH})$ from a commercial T. delbrueckii yeast blend (Viniflora ${ }^{\circledR}$ Harmony. nsac, CHR Hansen, Denmark) and one $S$. cerevisiae reference strain (VIN 13, Anchor Bio-Technologies, South Africa) were selected for the production of white and red wines. The $T$. delbrueckii strain selection was based on data from a laboratory-scale study (Van Breda et al., 2013). All yeasts were maintained on yeast peptone dextrose agar (YPD agar, Biolab, Merck South Africa) slants and stored at $4^{\circ} \mathrm{C}$ until required.

\section{Yeast inoculum propagation}

A three-phase propagation procedure was used to grow the yeast inocula: $10 \mathrm{~mL}$ of YPD broth (Biolab, Merck, South Africa) at $30^{\circ} \mathrm{C}$ for 24 hours; $100 \mathrm{~mL}$ of YPD broth incubated at $30^{\circ} \mathrm{C}$ for eight hours on an orbital shaker (RO20, Gerhardt); and $900 \mathrm{~mL}$ of YPD broth inoculated with the preceding
$110 \mathrm{~mL}$ culture at room temperature $\left( \pm 20^{\circ} \mathrm{C}\right)$ overnight on a Gyrotory ${ }^{\circledR}$ shaker (G10, New Brunswick Scientific).

\section{Small-scale white and red vinifications}

A white grape variety, Chenin blanc $\left(22.15^{\circ} \mathrm{B}, 7 \mathrm{~g} / \mathrm{L}\right.$ total acidity (TA), $\mathrm{pH} 3.42$ ), and a red grape variety, Pinotage $\left(25.1^{\circ} \mathrm{B}, 6.3 \mathrm{~g} / \mathrm{L} \mathrm{TA}, \mathrm{pH} 3.38\right)$, were used for small-scale vinifications. All fermentations were performed in duplicate.

A standardised white wine production method was followed, according to which the Chenin blanc grapes were crushed, the juice and skins were pressed at 1 Bar and a sedimentation enzyme $(0.50 \mathrm{~g} / \mathrm{L}$, Ultrazym, Novozymes, Switzerland) and $\mathrm{SO}_{2}(50 \mathrm{mg} / \mathrm{L})$ were added. The clarified Chenin blanc must was dispensed into stainless steel containers (18 L per $20 \mathrm{~L}$ container) fitted with fermentation caps. Seventeen fermentation treatments were initiated, comprising single yeast inoculations and co-inoculations. Three T. delbrueckii yeast isolates (strains 654, 301 and $\mathrm{M} 2 / 1$ ) and the commercial T. delbrueckii yeast strain (TdH) were inoculated individually. Four $T$. delbrueckii yeast isolates (strains 206, 704, M2/15 and M2/27) were coinoculated with the $S$. cerevisiae reference strain. For the co-inoculated fermentations, T. delbrueckii was inoculated at zero hours, followed by inoculation with the $S$. cerevisiae reference strain at zero hours, 24 and 48 hours respectively. A reference sample inoculated with $S$. cerevisiae only was also included. Di-ammonium phosphate $(0.50 \mathrm{~g} / \mathrm{L})$ was added as a source of nitrogen. The fermentations were conducted at $15^{\circ} \mathrm{C}$ and monitored by measuring $\mathrm{CO}_{2}$ weight loss. The fermentations were allowed to continue until the wines were dry.

The red wine production method was also standardised as described by Minnaar et al. (2015). Four T. delbrueckii yeast isolates (strains 654, 206, 301 and M2/1) were inoculated individually. The remaining three $T$. delbrueckii yeast isolates (strains 704, M2/19 and M2B/27) and the commercial $T$. delbrueckii yeast strain $(\mathrm{TdH})$ were inoculated in combination with the $S$. cerevisiae reference strain. The timing strategy for the co-inoculated fermentation was the same as that for Chenin blanc, and a S. cerevisiae reference fermentation was also included. Residual sugar analyses were performed on all wines to confirm the end of fermentation. After bottling, the wines were stored at $15^{\circ} \mathrm{C}$ until required for sensory evaluation and chemical analyses.

Isolation and identification of yeast from white wine lees After racking, lees samples were taken from the stainless steel fermentation containers of the single-inoculant Chenin blanc wines and preserved cryogenically in glycerol at $-80^{\circ} \mathrm{C}$. These lees samples were inoculated $(5 \mu \mathrm{L})$ into D-mannitol broth (4 g mannitol, $1.34 \mathrm{~g}$ yeast nitrogen base, Merck, South Africa) and incubated at room temperature $\left( \pm 20^{\circ} \mathrm{C}\right)$ for five to seven days. Once sufficient growth was observed, $10 \mu \mathrm{L}$ of the D-mannitol broth was streaked out onto lysine medium (Biolab, Merck, South Africa) and incubated at room temperature $\left( \pm 20^{\circ} \mathrm{C}\right)$ for five days. Single colonies were then further purified by streaking onto YPD agar (Biolab, Merck, South Africa) plates, followed by incubation at $30^{\circ} \mathrm{C}$ for three days.

The BioMeriéux identification system (ID32C, 
BioMeriéux, South Africa) with manual reading was used to identify the colonies according to the manufacturer's instructions. The identities supplied by the apiweb ${ }^{\mathrm{TM}}$ identification software were used as a presumptive identification. The identification was confirmed by CHEF gel electrophoresis, as described in Van Breda et al. (2013).

\section{Chemical analyses and sensory evaluation}

The wines were analysed for alcohol, volatile acidity (VA) (Koelenhof Wynlaboratorium, South Africa), glycerol (Winescan, Institute for Wine Biotechnology, Stellenbosch University), reducing sugar (Rebelein method) and $\mathrm{SO}_{2}$ (Ripper method). The wet chemistry methods were according to the methods prescribed by the South African Wine Laboratories Association (Anonymous, 2002). Five months after bottling, two different panels of 13 expert wine tasters sensorially evaluated all the wines. The wines were presented to the tasters based on a randomised block design, and descriptive sensory analysis was performed by scoring each sample on a $10 \mathrm{~cm}$ unstructured line scale. The descriptors used were: "fruity and fermentation aroma", "guava aroma", "body" and "general quality" for Chenin blanc, and "berry/cherry/plum aroma", "body" and "general quality" for Pinotage.

\section{Statistical analysis}

The experimental design was a completely randomised design. Data (chemical and sensory) were subjected to analysis of variance (ANOVA) using PROC GLM of the SAS ${ }^{\circledR}$ software (Version 9.2; SAS Institute Inc., Cary, USA). A Shapiro-Wilk test was used to verify the normality of the standardised residuals of the variables (Shapiro \& Wilk, 1965). Fisher's least significant difference was calculated at the 5\% level to compare treatment (yeast) means (Ott \& Longnecker, 2001). A probability level of 5\% was considered significant for all significance tests. Principal component analysis (PCA), using the correlation matrix, was performed on the sensory and chemical data separately by XLSTAT (version 2015.1.03.15485, Addinsoft, New York, USA) to examine the relationships among and between the variables and observations

\section{RESULTS AND DISCUSSION}

In comparison to $S$. cerevisiae, the deliberate use of non-Saccharomyces yeast in wine production is in its relative infancy. While an estimated 150 to 200 commercial $S$. cerevisiae yeasts are available to the wine industries worldwide, there are only a limited number of commercial T. delbrueckii strains (Jolly et al., 2014). These strains are all recommended for use as co-inoculants, usually with a specific $S$. cerevisiae strain. Although the number of commercial $T$. delbrueckii strains will probably never reach that of $S$. cerevisiae, there is undoubtedly scope for strains with improved oenological characteristics (Velázquez et al., 2015). The selection of yeasts used for this study was based on their individual performance and fermentation characteristics during a laboratory-scale investigation (Van Breda et al., 2013). It was found that considerable variation occurred in the fermentation characteristics of the $T$. delbrueckii strains investigated. While most were unable to completely utilise all the grape sugar, some had the potential to complete the fermentation as a single inoculant under the conditions tested. The length of the fermentations ranged from 14 to 32 days (Van Breda et al., 2013), which, for the faster fermenting yeasts, is comparable to other published work, where fermentations were found to take between 14 and 24 days (Belda et al., 2015; Loira et al., 2015). Consequently, the choice of strains for this investigation included weaker fermenters for co-inoculation, and the more vigorous fermenters for single inoculations.

The choice of the internationally lesser known grape varieties, Chenin blanc and Pinotage, for the investigation was made due to these two varieties being of economic and traditional importance to the South African wine industry. Chenin blanc is the most widely planted cultivar and is used to make a variety of wine styles and products. Pinotage, a hybrid between Pinot noir and Cinsaut, was bred in South Africa and is therefore considered a true South African variety. Both varieties deliver wines of varying quality, so an enhancement of wine quality is often sought.

\section{Small-scale vinification: Chenin blanc}

From the fermentation curves of the small-scale vinifications, it can be seen that all the co-inoculated fermentations (Groups 1 and 2) fermented faster (14 days) that the single T. delbrueckii inoculant fermentations (Group 3) (32 days) (Fig. 1). The duration of these co-inoculated fermentations is similar to that in other studies, which took between 12 and 24 days, but the single-inoculant group took much longer (24 vs. 32 days) (Azzolini et al., 2015; Belda et al., 2015). The zero-hour co-inoculations fermented at the same rate (slope of logarithmic growth phase) as the $S$. cerevisiae reference yeast. The 24-hour co-inoculations fermented for an intermediate length of time, and the 48-hour fermentations were the slowest. The single-inoculated fermentations also had a notably longer lag phase than the co-inoculated fermentations. This was expected, as it is known that the T. delbrueckii yeasts are slower fermenters and take longer than $S$. cerevisiae to acclimatise to the conditions of the grape must (Bely et al., 2008; Van Breda et al., 2013). Longer lag phases have also been linked to a positive association with the fruitiness and complexity of wine (Albertin et al., 2017). Three of the $T$. delbrueckii single fermentations (strains 301, 654 and M2/1) appeared to ferment at a similar rate and finished within 32 days, only slightly longer than the commercial $T$. delbrueckii yeast $(\mathrm{TdH})$.

All the wines fermented to dryness (sugar $\leq 5 \mathrm{~g} / \mathrm{L}$ ), in accordance with South African legislation, with one exception that was very close to dryness $(5.45 \mathrm{~g} / \mathrm{L})$ (Table 1$)$. The low sugars in the co-inoculated wines can be ascribed to the $S$. cerevisiae yeast completing the fermentation. The T. delbrueckii single-inoculant wines had, as was expected, the highest residual sugar, ranging from 2.60 to $5.45 \mathrm{~g} / \mathrm{L}$, indicating that the $T$. delbrueckii single-inoculant strategy could lead to complete fermentations, as also shown in the laboratory-scale trials using a sterile must (Van Breda et al., 2013). However, as the trials in this study were conducted in a non-sterile must, a possible background $S$. cerevisiae yeast population could have played a role. The alcohol levels of the various treatments were very similar, and a one-way ANOVA 


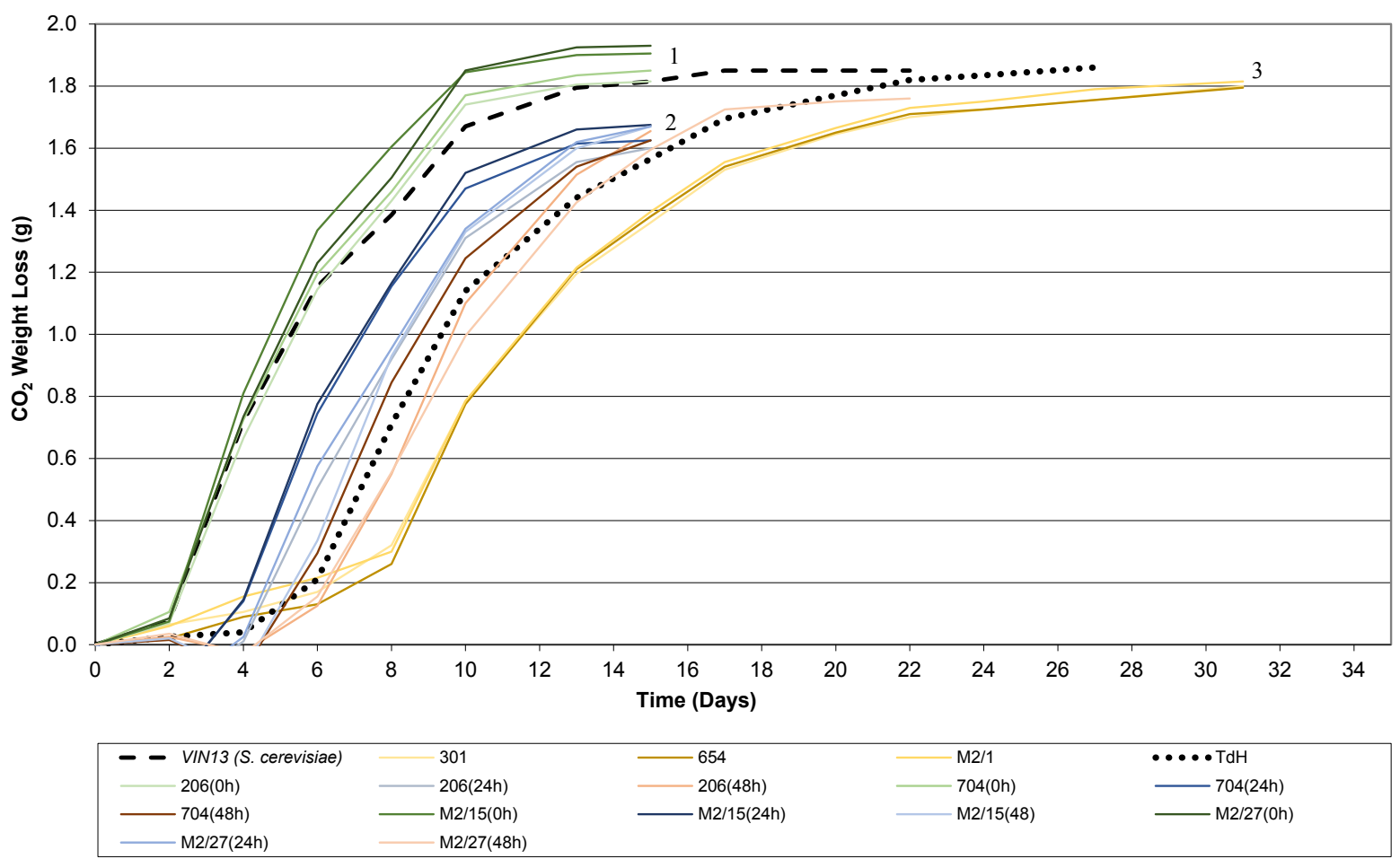

FIGURE 1

Average fermentation curves of duplicate small-scale Chenin blanc wines fermented at $15^{\circ} \mathrm{C}$. The co-inoculated fermentations are indicated in the legend by the time of Saccharomyces cerevisiae, strain VIN 13 inoculation (Group $1=0 \mathrm{~h}$ [zero hours]; Group $2=24 \mathrm{~h}$ [24 hours after start]; Group $3=48 \mathrm{~h}$ [48 hours after start]).

TABLE 1

Chemical profiles of Chenin blanc wines produced in small-scale fermentations at $15^{\circ} \mathrm{C}^{1}$

\begin{tabular}{|c|c|c|c|c|c|c|}
\hline \multirow[b]{2}{*}{ Yeast strains $^{2}$} & \multicolumn{6}{|c|}{ Chemical analyses } \\
\hline & $\begin{array}{c}\text { Residual } \\
\text { sugar }(g / L)\end{array}$ & $\begin{array}{l}\text { Alcohol } \\
(\%, v / v)\end{array}$ & $\begin{array}{c}\text { Glycerol } \\
(\mathrm{g} / \mathrm{L})\end{array}$ & $\begin{array}{c}\text { Total SO } \\
(\mathrm{mg} / \mathrm{L})\end{array}$ & $\begin{array}{c}\text { Volatile } \\
\text { acidity }(\mathrm{g} / \mathrm{L})\end{array}$ & $\begin{array}{c}\text { Total } \\
\text { acidity }(\mathrm{g} / \mathrm{L})\end{array}$ \\
\hline VIN 13 (S. cerevisiae reference) & $1.00 \pm 1.41$ & $13.31 \pm 0.04$ & $5.54 \pm 0.21$ & $114.05 \pm 1.63$ & $0.25 \pm 0.01$ & $5.35 \pm 0.06$ \\
\hline Harmony (commercial reference) & $2.60 \pm 2.55$ & $12.99 \pm 0.40$ & $6.67 \pm 0.21$ & $145.80 \pm 6.08$ & $0.35 \pm 0.06$ & $5.73 \pm 0.13$ \\
\hline 301 & $5.45 \pm 0.07$ & $13.04 \pm 0.00$ & $6.93 \pm 0.17$ & $121.05 \pm 10.68$ & $0.37 \pm 0.00$ & $5.61 \pm 0.02$ \\
\hline 654 & $4.85 \pm 0.21$ & $12.78 \pm 0.39$ & $6.41 \pm 0.69$ & $167.20 \pm 6.08$ & $0.35 \pm 0.04$ & $5.70 \pm 0.20$ \\
\hline $\mathrm{M} 2 / 1$ & $4.85 \pm 0.78$ & $13.07 \pm 0.03$ & $6.85 \pm 0.29$ & $156.25 \pm 20.86$ & $0.36 \pm 0.01$ & $5.59 \pm 0.02$ \\
\hline $206(0 \mathrm{~h})$ & $1.60 \pm 0.00$ & $13.28 \pm 0.01$ & $5.56 \pm 0.22$ & $137.85 \pm 5.44$ & $0.26 \pm 0.03$ & $5.27 \pm 0.02$ \\
\hline $206(24 \mathrm{~h})$ & $0.75 \pm 0.07$ & $13.24 \pm 0.02$ & $6.18 \pm 0.09$ & $105.40 \pm 4.81$ & $0.27 \pm 0.01$ & $5.42 \pm 0.03$ \\
\hline $206(48 \mathrm{~h})$ & $2.39 \pm 0.42$ & $13.16 \pm 0.02$ & $6.28 \pm 0.06$ & $131.71 \pm 2.05$ & $0.31 \pm 0.03$ & $5.49 \pm 0.13$ \\
\hline 704 (0 h) & $0.75 \pm 0.21$ & $13.24 \pm 0.01$ & $5.33 \pm 0.07$ & $128.35 \pm 1.34$ & $0.28 \pm 0.01$ & $5.27 \pm 0.01$ \\
\hline 704 (24 h) & $0.95 \pm 0.07$ & $13.28 \pm 0.04$ & $5.69 \pm 0.06$ & $112.45 \pm 1.91$ & $0.27 \pm 0.01$ & $5.35 \pm 0.00$ \\
\hline $704(48 \mathrm{~h})$ & $0.90 \pm 0.00$ & $13.23 \pm 0.03$ & $5.94 \pm 0.63$ & $120.85 \pm 3.61$ & $0.29 \pm 0.04$ & $5.42 \pm 0.14$ \\
\hline $\mathrm{M} 2 / 15(0 \mathrm{~h})$ & $1.05 \pm 0.07$ & $13.15 \pm 0.06$ & $5.57 \pm 0.35$ & $124.35 \pm 14.92$ & $0.29 \pm 0.03$ & $5.26 \pm 0.02$ \\
\hline $\mathrm{M} 2 / 15(24 \mathrm{~h})$ & $0.95 \pm 0.92$ & $13.15 \pm 0.01$ & $5.71 \pm 0.09$ & $127.75 \pm 5.02$ & $0.28 \pm 0.01$ & $5.36 \pm 0.01$ \\
\hline M2/15 (48 h) & $1.00 \pm 0.00$ & $13.13 \pm 0.06$ & $6.67 \pm 0.53$ & $117.60 \pm 4.53$ & $0.37 \pm 0.01$ & $5.75 \pm 0.16$ \\
\hline $\mathrm{M} 2 / 27(0 \mathrm{~h})$ & $1.05 \pm 0.07$ & $13.22 \pm 0.04$ & $5.37 \pm 0.09$ & $113.75 \pm 3.32$ & $0.28 \pm 0.01$ & $5.27 \pm 0.01$ \\
\hline M2/27 (24 h) & $1.20 \pm 0.28$ & $13.20 \pm 0.04$ & $6.01 \pm 0.21$ & $120.45 \pm 4.45$ & $0.27 \pm 0.03$ & $5.44 \pm 0.05$ \\
\hline M2/27 (48 h) & $0.20 \pm 0.28$ & $13.30 \pm 0.04$ & $5.82 \pm 0.04$ & $109.95 \pm 3.18$ & $0.27 \pm 0.01$ & $5.51 \pm 0.01$ \\
\hline
\end{tabular}

${ }^{1}$ Means \pm standard deviation $(\mathrm{n}=2)$

${ }^{2}$ Yeast strains used and time of co-inoculation with S. cerevisiae 
performed on the alcohol data showed that the differences were not significant (results not shown). The alcohol levels were only lower where less sugar was consumed, showing that these T. delbrueckii isolates are not suitable as a means for lowering the alcohol content of the wine. This is in contrast to other published works where, $T$. delbrueckii vinifications produced between $0.14 \%$ and $0.47 \%$ lower alcohol levels than reference $S$. cerevisiae fermentations (Azzolini et al., 2015; Belda et al., 2015; Renault et al., 2015).

Glycerol produced by the single-inoculant fermentations was found to be slightly higher than in the co-inoculated wines and the $S$. cerevisiae reference fermentation, which is similar to what has been observed in other trials (Jolly et al., 2003a; Belda et al., 2015). The exception was the treatment of M2/15 (48 h), which was in the same range as the single inoculants (Table 1). Higher glycerol production has previously been shown for non-Saccharomyces yeasts (García et al., 2010; Romani et al., 2010; Loira, et al., 2015) and can contribute to improved mouthfeel, sweetness and complexity in wines (Ciani \& Maccarelli, 1998; Loira et al., 2015).

Total $\mathrm{SO}_{2}$ levels for the single-inoculant fermentations were higher than those of the co-inoculated fermentations and the $S$. cerevisiae reference fermentation (Table 1). This trait has previously been shown for single $T$. delbrueckii fermentations (Jolly et al., 2003a). High $\mathrm{SO}_{2}$ is not desirable, as this can negatively affect wine quality and inhibit subsequent malolactic fermentation by sensitive lactic acid bacteria (Lerm et al., 2010). Although the $\mathrm{SO}_{2}$ levels were higher for the single-inoculant wines, all except one fell well within the legal limits for South African wine standards (< $160 \mathrm{mg} / \mathrm{L}$ ) (South African Liquor Products Act 60 of 1989) (Anonymous, 1989).

The volatile acidity produced by the single-inoculant fermentations was similar to that of the wines produced by the co-inoculated fermentations and slightly higher than the $S$. cerevisiae reference fermentation (Table 1). However, all the values fell within the legal limit for South African wines ( $\leq 1.2 \mathrm{~g} / \mathrm{L}$ ) (Anonymous, 1989). The higher values were not expected, as it has been mostly reported that $T$. delbrueckii strains generally produce lower levels of volatile acidity (Lafon-Lafourcade, 1983; Bely et al., 2008; Renault et al. 2009; Azzolini et at., 2015). However, some reports show higher levels of acetic acid (major component of volatile acidity) for single-inoculant $T$. delbrueckii wines compared to reference $S$. cerevisiae wines (Belda et al., 2015).

The TA values for both single and co-inoculated fermentations (5.27 to $5.76 \mathrm{~g} / \mathrm{L})$ showed no notable differences. However, this varied from previously published work, in which TA levels for T. delbrueckiionly fermentations were lower than those of $S$. cerevisiae and mixed fermentations (Belda et al., 2015). However, it is generally accepted that yeasts do not affect tartaric acid levels (the most abundant acid in grapes).

The PCA of the sensory data (Fig. 2) showed that the coinoculated treatments grouped together with the $S$. cerevisiae reference treatment. These were clearly separated from the single inoculation treatments, which appeared on the far right of the plot. The PCA analyses of the standard wine chemical data (Fig. 3) showed a similar grouping, confirming the different profiles obtained with the single-inoculation treatments compared to the co-inoculation and $S$. cerevisiae treatments.

The sensory descriptors "fruity and fermentation", "guava" and "body" were most prominent in the singleinoculant small-scale wines produced from the T. delbrueckii yeast isolates (strains 654 and M2/1) (Fig. 2). The PCA results for the sensory evaluation were complemented by the ANOVA results (Table 2), which showed that the wine made from yeast strain 654 often scored significantly higher

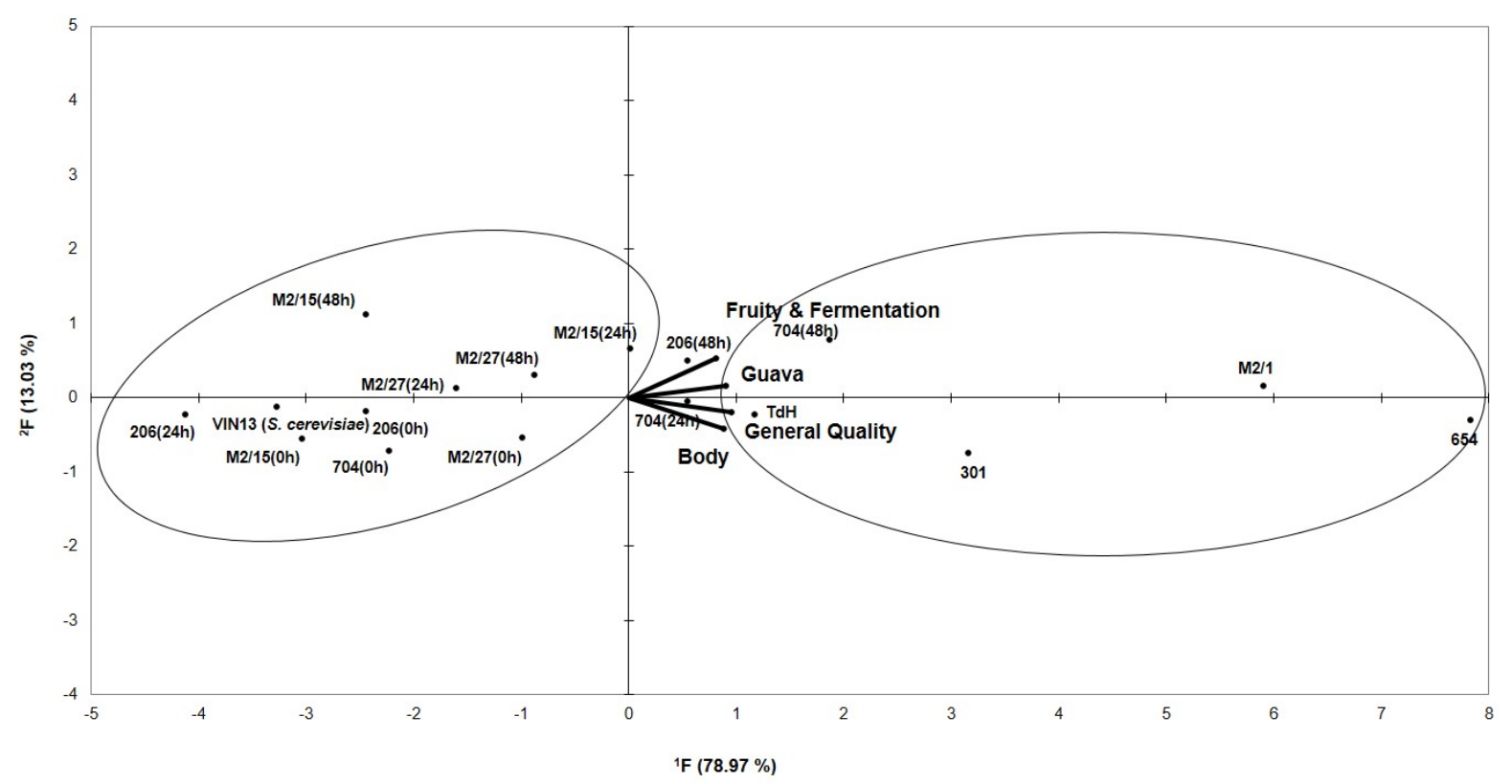

FIGURE 2

Principal component analysis of the average sensory analysis data $(n=2)$ for Chenin blanc wines.

${ }^{\mathrm{F} 1}$ First principal component; ${ }^{\text {F2 }}$ Second principal component 
TABLE 2

Sensory analyses of Chenin blanc wines produced in small-scale fermentations with single Torulaspora delbrueckii inocula or co-inoculated with Saccharomyces cerevisiae at different times.

\begin{tabular}{|c|c|c|c|c|}
\hline Yeast strain ${ }^{1}$ & $\begin{array}{c}\text { Fruity \& } \\
\text { fermentation }\end{array}$ & Guava & Body & General quality \\
\hline VIN 13 (S. cerevisiae reference) & $46 c d^{2}$ & $33 \mathrm{bc}$ & 44de & $43 c$ \\
\hline Harmony (Commercial T. delbrueckii) & $52 \mathrm{abcd}$ & $35 \mathrm{abc}$ & $51 \mathrm{bcd}$ & $49 \mathrm{bc}$ \\
\hline 301 & $50 \mathrm{abcd}$ & $38 \mathrm{abc}$ & $53 \mathrm{abc}$ & $54 \mathrm{ab}$ \\
\hline 654 & $57 \mathrm{ab}$ & $43 \mathrm{a}$ & $58 \mathrm{a}$ & $58 \mathrm{a}$ \\
\hline $\mathrm{M} 2 / 1$ & $58 \mathrm{a}$ & $40 \mathrm{ab}$ & $54 \mathrm{ab}$ & $56 a$ \\
\hline $206(0 \mathrm{~h})$ & $47 \mathrm{bcd}$ & $33 \mathrm{bc}$ & $45 \mathrm{de}$ & $45 c$ \\
\hline $206(24 \mathrm{~h})$ & $46 \mathrm{~cd}$ & $30 \mathrm{c}$ & $43 \mathrm{de}$ & $44 \mathrm{c}$ \\
\hline 206 (48 h) & $54 \mathrm{abcd}$ & $35 \mathrm{abc}$ & $46 \mathrm{~d}$ & $49 \mathrm{bc}$ \\
\hline $704(0 \mathrm{~h})$ & $45 d$ & $33 \mathrm{bc}$ & $48 \mathrm{bcd}$ & $45 \mathrm{c}$ \\
\hline $704(24 \mathrm{~h})$ & $50 \mathrm{abcd}$ & $37 \mathrm{abc}$ & $48 \mathrm{bcd}$ & $48 \mathrm{bc}$ \\
\hline 704 (48 h) & $57 \mathrm{ab}$ & $37 \mathrm{abc}$ & $49 \mathrm{bcd}$ & $47 \mathrm{c}$ \\
\hline $\mathrm{M} 2 / 15(0 \mathrm{~h})$ & $46 \mathrm{~cd}$ & $31 \mathrm{bc}$ & $47 \mathrm{~cd}$ & $44 c$ \\
\hline M2/15 (24 h) & $55 \mathrm{abc}$ & $34 a b c$ & 46de & $47 \mathrm{c}$ \\
\hline M2/15 (48 h) & $51 \mathrm{abcd}$ & $36 a b c$ & $39 \mathrm{e}$ & $43 c$ \\
\hline $\mathrm{M} 2 / 27(0 \mathrm{~h})$ & $46 \mathrm{~cd}$ & $35 a b c$ & $47 \mathrm{~cd}$ & $48 \mathrm{bc}$ \\
\hline M2/27 (24 h) & $48 \mathrm{bcd}$ & $36 a b c$ & $45 \mathrm{de}$ & $44 \mathrm{c}$ \\
\hline M2/27 (48 h) & 49abcd & $37 \mathrm{abc}$ & 44de & $46 c$ \\
\hline
\end{tabular}

${ }^{1}$ Yeast strains used and time of co-inoculation with $S$. cerevisiae

${ }^{2}$ Values within columns followed by the same letter do not differ significantly $(\mathrm{p}>0.05)$

in terms of its "guava" aroma note, "body" (mouthfeel) and "general quality". Wines produced from the T. delbrueckii strain M2/1 treatment also had high scores and were often judged to be significantly better than the other wines in terms of the "fruity and fermentation" character and "general quality" (Table 2). These results correspond to the findings of previous studies, which found that non-Saccharomyces yeasts contributed to mouthfeel and improved the quality of wines (Ciani \& Picciotti, 1995; Ciani \& Maccarelli, 1998; Minnaar et al., 2015; Ngqumba et al., 2017). The results also support the findings of Albertin et al. (2017) on the already mentioned link between non-Saccharomyces yeasts, the duration of the $S$. cerevisiae lag phase and the wine's fruitiness and complexity. The reference $S$. cerevisiae wine had amongst the lowest sensory scores of all the wines (Table 2).

\section{Small-scale vinification: Pinotage}

The Pinotage fermentations were all completed within five days. Of note is that, in contrast to the Chenin blanc wines, all the T. delbrueckii single-inoculated treatments fermented dry (under $4 \mathrm{~g} / \mathrm{L}$ residual sugar) (Table 3 ). However, the contribution by the $S$. cerevisiae natural population cannot be discounted (the red wine production process is more susceptible to contamination by resident $S$. cerevisiae cellar populations). T. delbrueckii contributed to a considerably higher total $\mathrm{SO}_{2}$ in the white wines, while this was not evident in the red wines. The results of the analyses of the other routine wine parameters were very similar to the $S$. cerevisiae reference wine. The sensory results showed no notable differences in the wines, especially in "general quality" and "body" (Table 4), as was also observed in the white wine trial. The PCA of the sensory and chemical data (Figs 4 and 5) showed no trends regarding inoculation times or single vs. co-inoculations. This therefore reinforces the observation that $T$. delbrueckii may have been dominated by the growth of the natural $S$. cerevisiae background resident population.

\section{Isolation and identification of yeast from wine lees}

Wine lees samples of the single-inoculant treatments were inoculated into D-mannitol broth to enrich for, and isolate, $T$. delbrueckii yeasts, since $S$. cerevisiae is unable to utilise mannitol (Kurtzman, 2011; Vaughan-Martini \& Martini, 2011). The use of lysine agar served as a further selective medium for non-Saccharomyces yeast, and colonies differing in appearance were observed, i.e. white and cream. The white colonies gave the desired identification of Candida colliculosa (anamorph of T. delbrueckii) with a 99.9\% probability. However, C. colliculosa could only be isolated from the lees of the wine made from yeast strain 654, and not from the other single-inoculant wines. 


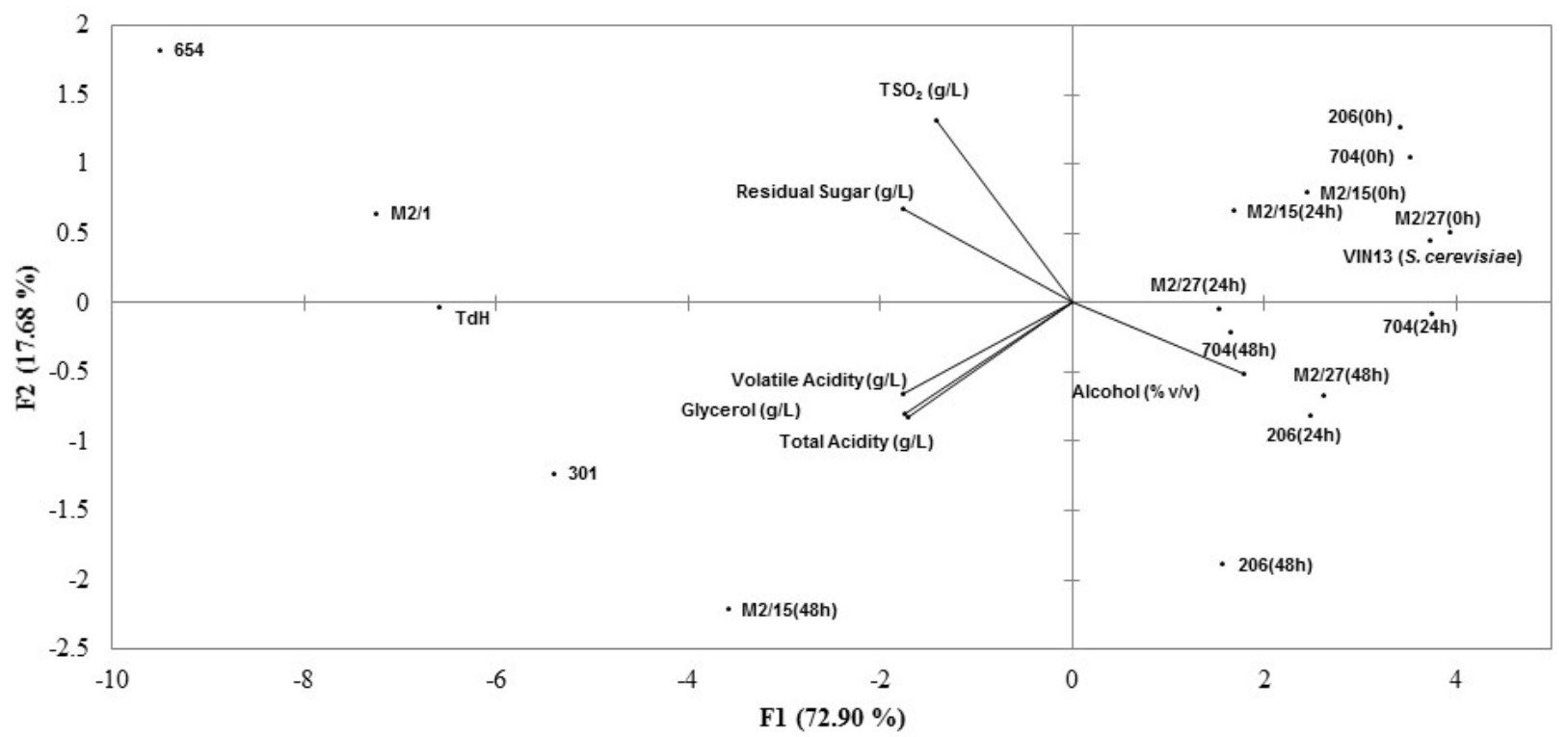

FIGURE 3

PCA bi-plot of chemical analyses $(n=2)$ of Chenin blanc wines, illustrating the yeasts that group together for specific compounds produced. ${ }^{\mathrm{F} 1}$ First principal component; ${ }^{\mathrm{F} 2}$ Second principal component

TABLE 3

Average data of chemical analyses of Pinotage wines produced in small-scale fermentations with different combinations of yeast at $24^{\circ} \mathrm{C}^{1}$

\begin{tabular}{|c|c|c|c|c|c|c|}
\hline \multirow[b]{2}{*}{ Yeast strain ${ }^{2}$} & \multicolumn{6}{|c|}{ Chemical analyses } \\
\hline & $\begin{array}{c}\text { Residual } \\
\operatorname{sugar}(g / L)\end{array}$ & $\begin{array}{l}\text { Alcohol } \\
(\%, v / v)\end{array}$ & $\begin{array}{c}\text { Glycerol } \\
\text { (g/L) }\end{array}$ & $\begin{array}{c}\text { Total SO } \\
(\mathrm{mg} / \mathrm{L})\end{array}$ & $\begin{array}{c}\text { Volatile } \\
\text { acidity (g/L) }\end{array}$ & $\begin{array}{c}\text { Total acidity } \\
\text { (g/L) }\end{array}$ \\
\hline VIN 13 (S. cerevisiae reference) $)^{3}$ & $2.00 \pm 0.49$ & $15.10 \pm 0.35$ & $10.30 \pm 0.25$ & $79.00 \pm 4.24$ & $0.36 \pm 0.04$ & $5.64 \pm 0.08$ \\
\hline 654 & $2.20 \pm 0.13$ & $15.10 \pm 0.01$ & $9.36 \pm 0.08$ & $76.00 \pm 5.66$ & $0.38 \pm 0.01$ & $5.57 \pm 0.13$ \\
\hline M2/1 & $5.00 \pm 0.03$ & $14.78 \pm 0.16$ & $8.87 \pm 0.27$ & $78.00 \pm 1.41$ & $0.38 \pm 0.00$ & $5.60 \pm 0.01$ \\
\hline 206 & $6.40 \pm 0.04$ & $14.87 \pm 0.01$ & $9.40 \pm 0.06$ & $80.00 \pm 8.49$ & $0.38 \pm 0.03$ & $5.65 \pm 0.06$ \\
\hline 301 & $4.00 \pm 0.20$ & $14.84 \pm 0.02$ & $9.00 \pm 0.15$ & $72.50 \pm 10.61$ & $0.40 \pm 0.01$ & $5.63 \pm 0.01$ \\
\hline $\mathrm{TdH}(0 \mathrm{~h})$ & $2.40 \pm 0.45$ & $15.22 \pm 0.25$ & $9.80 \pm 0.10$ & $86.50 \pm 2.83$ & $0.40 \pm 0.02$ & $5.61 \pm 0.05$ \\
\hline $\mathrm{TdH}(24 \mathrm{~h})$ & $4.60 \pm 0.20$ & $14.72 \pm 0.01$ & $9.60 \pm 0.18$ & $86.00 \pm 7.07$ & $0.36 \pm 0.01$ & $5.74 \pm 0.06$ \\
\hline $\mathrm{TdH}(48 \mathrm{~h})$ & $6.40 \pm 0.28$ & $14.84 \pm 0.19$ & $9.73 \pm 0.06$ & $84.00 \pm 1.41$ & $0.36 \pm 0.04$ & $5.76 \pm 0.01$ \\
\hline $704(0 \mathrm{~h})$ & $6.00 \pm 0.10$ & $14.81 \pm 0.33$ & $9.39 \pm 0.31$ & $63.00 \pm 0.71$ & $0.36 \pm 0.01$ & $5.59 \pm 0.02$ \\
\hline $704(24 \mathrm{~h})$ & $6.40 \pm 0.04$ & $15.22 \pm 0.08$ & $10.11 \pm 0.11$ & $67.00 \pm 1.41$ & $0.36 \pm 0.01$ & $5.64 \pm 0.03$ \\
\hline $704(48 \mathrm{~h})$ & $1.80 \pm 0.40$ & $14.90 \pm 0.11$ & $9.70 \pm 0.25$ & $71.00 \pm 0.00$ & $0.36 \pm 0.02$ & $5.71 \pm 0.04$ \\
\hline M2/19 (0 h) & $4.80 \pm 0.48$ & $14.74 \pm 0.04$ & $9.48 \pm 0.20$ & $58.00 \pm 19.80$ & $0.37 \pm 0.04$ & $5.58 \pm 0.06$ \\
\hline M2/19 (24 h) & $3.60 \pm 0.78$ & $14.45 \pm 0.09$ & $9.70 \pm 0.05$ & $61.00 \pm 28.28$ & $0.36 \pm 0.03$ & $5.75 \pm 0.00$ \\
\hline M2/19 (48 h) & $5.00 \pm 0.04$ & $14.81 \pm 0.16$ & $9.96 \pm 0.54$ & $52.00 \pm 24.04$ & $0.32 \pm 0.04$ & $5.82 \pm 0.02$ \\
\hline $\mathrm{M} 2 \mathrm{~B} / 27(0 \mathrm{~h})$ & $4.80 \pm 1.24$ & $14.69 \pm 0.01$ & $9.76 \pm 0.16$ & $80.00^{3}$ & $0.41 \pm 0.06$ & $5.66 \pm 0.01$ \\
\hline M2B/27 (24 h) & $3.40 \pm 0.06$ & $14.49 \pm 0.06$ & $9.80 \pm 0.09$ & $76.00 \pm 4.24$ & $0.36 \pm 0.03$ & $5.76 \pm 0.06$ \\
\hline $\mathrm{M} 2 \mathrm{~B} / 27$ (48 h) & $4.80 \pm 0.47$ & $14.29 \pm 0.19$ & $9.75 \pm 0.10$ & $65.00 \pm 8.49$ & $0.36 \pm 0.01$ & $5.78 \pm 0.11$ \\
\hline
\end{tabular}

${ }^{1}$ Means \pm standard deviation $(\mathrm{n}=2)$.

${ }^{2}$ Yeast strains used. Time of co-inoculation with $S$. cerevisiae indicated in brackets.

${ }^{3}$ Only one sample. 
Six of the re-isolated $C$. colliculosa colonies were subjected to CHEF gel electrophoresis to compare them to the profile of the yeast initially inoculated at the start of the fermentation. The chromosomal banding patterns of three of the yeasts matched (lanes 6 to 8 in Fig. 6), confirming that the inoculated strain 654 was responsible for these fermentations. Three isolates appeared similar, but had an extra band (as indicated by the arrows in Fig. 6). This could possibly be due to the selected $T$. delbrueckii colonies being yeasts that were naturally present in the must. Despite the failure to isolate yeasts from the other single-inoculant treatments, the various PCA analyses of the chemical

Biplot (axes F1 and F2: $95.83 \%$ )

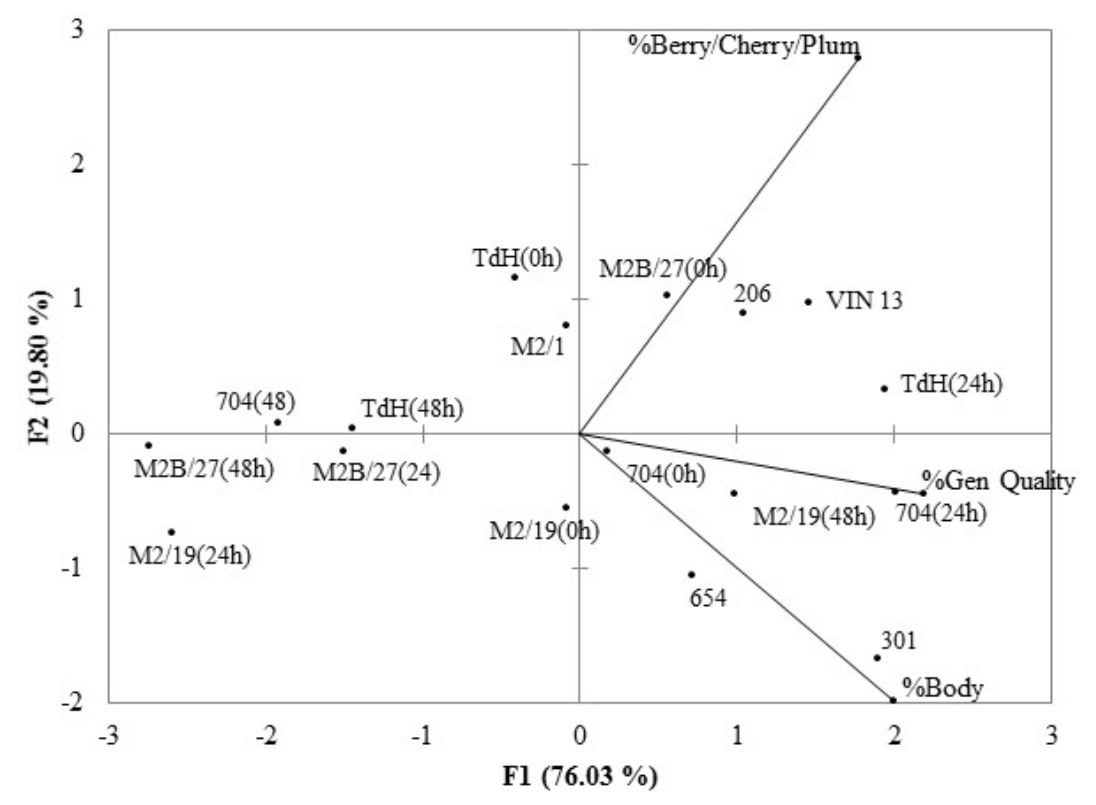

FIGURE 4

Principal component analysis of the average sensory analysis data $(n=2)$ for Pinotage wines.

${ }^{\mathrm{F} 1}$ First principal component; ${ }^{\mathrm{F} 2}$ Second principal component

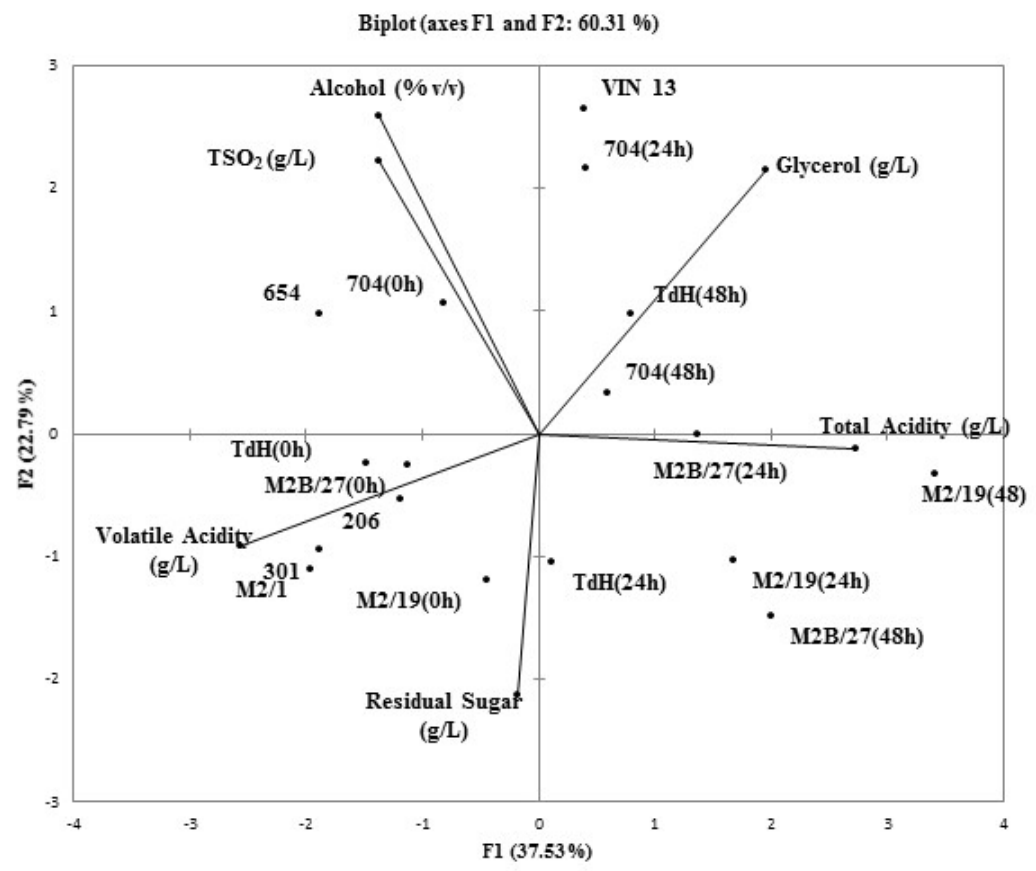

FIGURE 5

Principal component analysis of the average chemical analysis data $(n=2)$ for Pinotage wines.

${ }^{\mathrm{F} 1}$ First principal component; ${ }^{\mathrm{F} 2}$ Second principal component 
TABLE 4

Sensory analyses of Pinotage wines produced in small-scale fermentations with different combinations of yeast.

\begin{tabular}{|c|c|c|c|}
\hline Yeast strain $^{1}$ & $\begin{array}{c}\text { Berry/cherry/ } \\
\text { plum aroma intensity }\end{array}$ & Body & General quality \\
\hline VIN 13 (S. cerevisiae references) & $61 \mathrm{a}^{2}$ & $54 \mathrm{a}$ & $52 \mathrm{ab}$ \\
\hline 654 & $51 \mathrm{abcd}$ & $56 a$ & $52 \mathrm{ab}$ \\
\hline $\mathrm{M} 2 / 1$ & $56 a b c$ & $50 \mathrm{a}$ & $49 \mathrm{ab}$ \\
\hline 206 & $58 \mathrm{ab}$ & $52 \mathrm{a}$ & $53 \mathrm{ab}$ \\
\hline 301 & $51 \mathrm{abcd}$ & $59 \mathrm{a}$ & $56 \mathrm{a}$ \\
\hline 704 \& VIN $13(0$ h) & $53 \mathrm{abcd}$ & $54 \mathrm{a}$ & $49 \mathrm{ab}$ \\
\hline 704 \& VIN 13 (24 h) & $56 a b c$ & $57 \mathrm{a}$ & $56 \mathrm{a}$ \\
\hline 704 \& VIN 13 (48 h) & $48 \mathrm{~cd}$ & $47 \mathrm{a}$ & $47 \mathrm{ab}$ \\
\hline Td Harmony \& VIN 13 (0 h) & $56 a b c$ & $48 \mathrm{a}$ & $50 \mathrm{ab}$ \\
\hline Td Harmony \& VIN 13 (24 h) & $58 \mathrm{ab}$ & $55 \mathrm{a}$ & $55 \mathrm{a}$ \\
\hline Td Harmony \& VIN 13 (48 h) & $49 \mathrm{bcd}$ & $48 \mathrm{a}$ & $48 \mathrm{ab}$ \\
\hline M2/19 \& VIN 13 (0 h) & $50 \mathrm{abcd}$ & $53 a$ & $50 \mathrm{ab}$ \\
\hline M2/19 \& VIN 13 (24 h) & $44 d$ & $49 \mathrm{a}$ & $43 b$ \\
\hline M2/19 \& VIN 13 (48 h) & $54 \mathrm{abcd}$ & $56 \mathrm{a}$ & $52 \mathrm{ab}$ \\
\hline M2B/27 \& VIN 13 (0 h) & $59 \mathrm{ab}$ & $53 \mathrm{a}$ & $49 \mathrm{ab}$ \\
\hline M2B/27 \& VIN 13 (24 h) & $49 \mathrm{bcd}$ & $49 \mathrm{a}$ & $46 a b$ \\
\hline M2B/27 \& VIN 13 (48 h) & $46 \mathrm{~cd}$ & $48 \mathrm{a}$ & $42 b$ \\
\hline
\end{tabular}

${ }^{1}$ Yeast strains used and time of co-inoculation with $S$. cerevisiae

${ }^{2}$ Values within columns followed by the same letter do not differ significantly $(\mathrm{p}<0.05)$

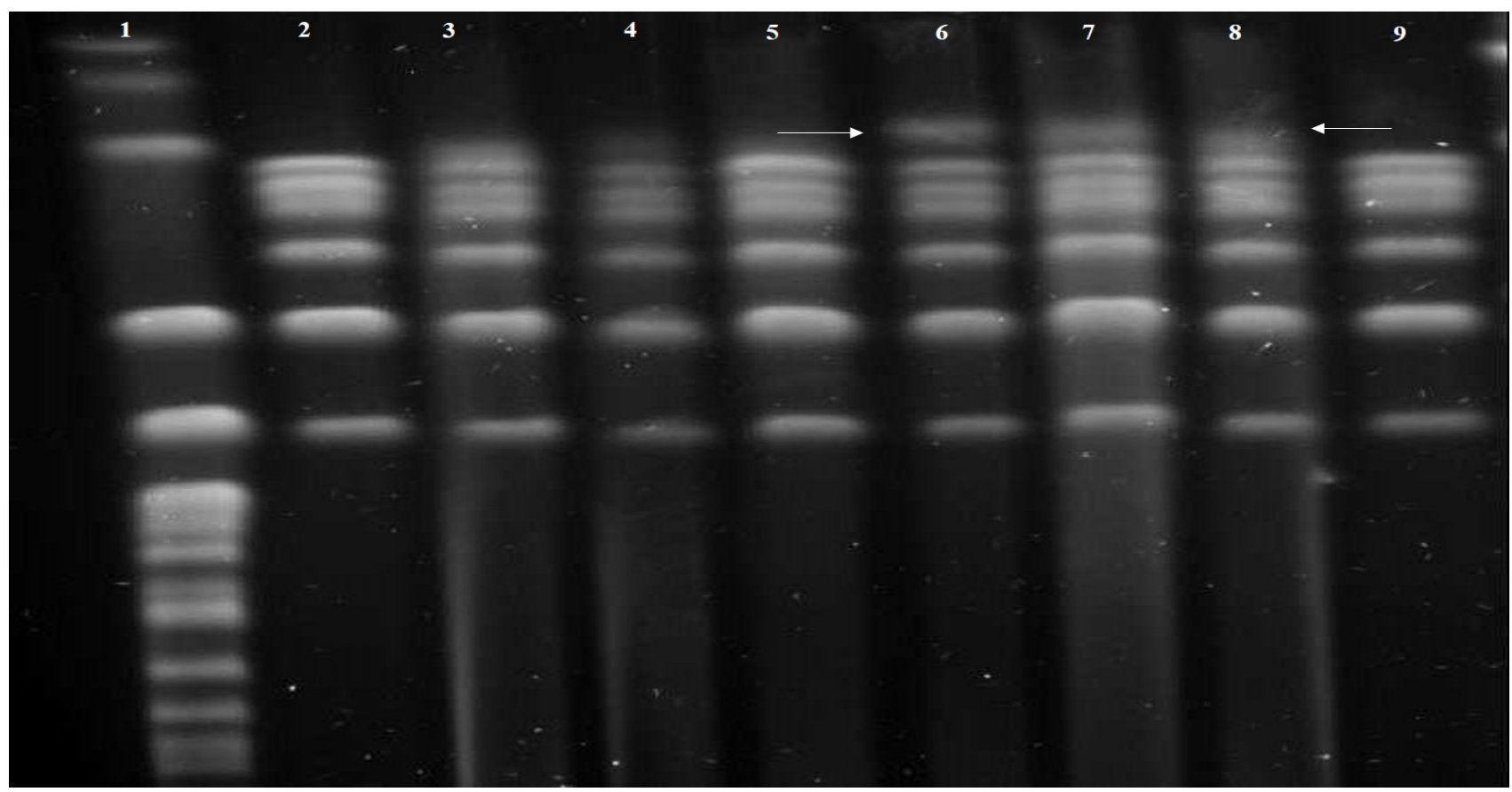

FIGURE 6

CHEF DNA profiles of the Torulaspora delbrueckii isolates in comparison to those isolated from the lees. Lanes 1: VIN 13 reference; Lanes 2 - 8: Seven isolates from lees 654; Lane 9: 654 mother culture (control). The extra bands are indicated by the white arrows. 
and sensory data, as previously shown, indicate that the T. delbrueckii strains were actively involved in the Chenin blanc fermentations, and their "fingerprint" is evident. The same cannot be concluded for the Pinotage treatments, where no T. delbrueckii "fingerprint" is evident, and in all probability the treatments were dominated by the natural $S$. cerevisiae populations. T. delbrueckii inhibition by $S$. cerevisiae has been shown by other authors (Taillandier et al., 2014; Albergaria \& Arneborg, 2016; Wang et al., 2016).

\section{CONCLUSIONS}

The various co-inoculation treatments all led to dry wines, and a $T$. delbrueckii chemical and sensory profile fingerprint was evident in the white wines. A similar fingerprint was not observed in the red wines. From the results obtained in this study, two out of the nine T. delbrueckii yeast strains (i.e. strains 654 and M2/1) appeared to show potential as singleinoculant yeasts in commercial white wine production. Strain 654 is the more robust of the two, as it could be re-isolated from the yeast lees after fermentation, confirming its activity to the end of the fermentation. However, the protocol used in the investigation was not successful in lowering the wine alcohol content significantly.

\section{LITERATURE CITED}

Albergaria, H. \& Arneborg, N., 2016. Dominance of Saccharomyces cerevisiae in alcoholic fermentation processes: Role of physiological fitness and microbial interactions. Appl. Microbiol. Biotechnol. 100, 2035-46.

Albertin, W., Zimmeer, A., Miot-Sertier, C., Bernard, M., Coulon, J., Moine, V., Colonna-Ceccaldi, B., Belu, M., Marullo, P. \& Masneuf-Pomarede, I., 2017. Combined effect of the Saccharomyces cerevisiae lag phase and the non-Saccharomyces consortium to enhance wine fruitiness and complexity. Appl. Microbiol. Biotechnol. 101, 7603-7620.

Alonso, A., Belda, I., Santos, A., Nevascués, E. \& Marquina, D., 2015. Advances in the control of the spoilage caused by Zygosaccharomyces species on sweet wines and concentrated grape musts. Food Cont. 51, 129134

Amerine, M.A. \& Kunkee, R.E., 1969. Microbiology of winemaking. Ann. Review Microbiol. 22, 324-328.

Anonymous, 1989. The Liquor Products Act, Regulation no 60 of 1989 [Online]: http://www.sawis.co.za [accessed on 27 June 2011].

Anonymous, 2002. Methods of analyses for wine laboratories. South African Wine Laboratories Association (SAWLA). HEH Signs, Bellville.

Azzolini, M., Tosi, E., Lorenzini, M., Finato, F. \& Zapparoli, G., 2015. Contribution to the aroma of white wines by controlled Torulaspora delbrueckii cultures in association with Saccharomyces cerevisiae. World J. Microbiol. Biotech. 31, 277-293.

Belda, I., Nevascués, E., Maquina, D., Santos, A., Calderon, F. \& Benito, S., 2015. Dynamic analysis of physiological properties of Torulaspora delbrueckii in wine fermentations and its incidence on wine quality. Appl. Microbiol. Biotech. 99, 1911-1922.

Bely, M., Stoeckle, P., Masneuf-Pomarède, I. \& Dubourdieu, D., 2008. Impact of mixed Torulaspora delbrueckii-Saccharomyces cerevisiae culture on high-sugar fermentation. Int. J. Food Microbiol. 122, 312-320.

Benito, Á., Calderón, F. \& Benito, S., 2017. The combined use of Schizosaccharomyces pombe and Lachancea thermotolerans - Effect of the anthocyanin wine composition. Mol. 22, 2-14.
Benito, Á., Jeffares D., Palomero, F., Calderón, F., Bai, F-Y, Bähler, J. \& Benito, S., 2016. Selected Schizosaccharomyces pombe strains have characteristics that are beneficial for winemaking. PLoS ONE 11(3), e0151102. doi:10.1371/journal.pone.0151102

Chen, D. \& Liu, S.Q., 2016. Impact of simultaneous and sequential fermentation with Torulaspora delbrueckii and Saccharomyces cerevisiae on non-volatiles and volatiles of lychee wine. LWT-Food Sci. Technol. 65, $53-61$.

Ciani., M. \& Comitini, F., 2011. Non-Saccharomyces wine yeasts have a promising role in biotechnological approaches to winemaking. Ann. Microbiol. 61, 25-32.

Ciani, M. \& Maccarelli, F., 1998. Oenological properties of non-Saccharomyces yeasts associated with wine-making. World J. Microbiol. Biotechnol. 14, 199-203.

Ciani, M., Beco, L. \& Comitini, F., 2006. Fermentation behaviour and metabolic interactions of multistarter wine yeast fermentations. Int. J. Food Microbiol. 108, 239-245.

Ciani, M. \& Picciotti, G., 1995. The growth kinetics and fermentation behaviour of some non-Saccharomyces yeasts associated with winemaking. Biotechnol. Lett. 17, 1247-1250.

Combina, M., Elía, A., Mercado, L., Catania, C., Ganga, A. \& Martinez, C., 2005. Dynamics of indigenous yeast populations during spontaneous fermentation of wines from Mendoza, Argentina. Int. J. Food Microbiol. 99, 237-243.

Comitini, F., Gobbi, M., Domizio, P., Romani, C., Lencioni, L., Mannazzu, I. \& Ciani, M., 2011. Selected non-Saccharomyces wine yeasts in controlled multistarter fermentations with Saccharomyces cerevisiae. Food Microbiol. $28,873-882$.

Deák, T., 2007 ( $2^{\text {nd }}$ ed). Handbook of food spoilage yeasts. CRC Press, Boca Raton.

Degré, R., 1993. Selection and commercial cultivation of wine yeast and bacteria. In: Fleet, G.H. (ed.). Wine microbiology and bacteriology. Taylor and Francis, New York, pp. $421-447$.

Domizio, P., Liu, Y., Bisson, L.F. \& Barile, D., 2017. Cell wall polysaccharides released during the alcoholic fermentation by Schizosaccharomyces pombe and S. japonicus: Quantification and characterization. Food Microbiol. 61, 136-149.

Egli, C.M., Edinger, W.D., Mitrakul, C.M. \& Henich-Kling, T., 1998. Dynamics of indigenous and inoculated yeast populations and their effect on the sensory character of Riesling and Chardonnay wines. J. Appl. Microbiol. 85, 779-789.

Erten, H. \& Campbell, I., 2001. The production of low-alcohol wines by aerobic yeasts. J. Inst. Brew. 107, 207-215.

Farías, M.E., Aredes Fernandez, P.A., Sosa, O.A. \& Manca de Nadra, M.C., 2003. Influence of non-Saccharomyces yeast growth on the metabolism of nitrogenous compounds in lactic acid bacteria from wine. Latin Am. Appl. Res. 33, 231-234.

Fleet, G.H., 2003. Yeast interactions and wine flavour. Int. J. Food Microbiol. 86, 11-22.

Fleet, G.H. \& Heard, G.M., 1993. Yeasts - Growth during fermentation In: Fleet, G.H. (ed.). Wine microbiology and biotechnology. Harwood Academic Publishers, Chur, Switzerland. pp. 27 - 54 .

García, V., Vásquez, H., Fonseca, F., Manzanares, P., Viana, F., Martínez, C. \& Ganga, M.A., 2010. Effects of using mixed wine yeast cultures in the production of Chardonnay wines. Rev. Argent. Microbiol. 42, 226-229. 
Granchi, L., Ganucci, D., Messini, A., Rosellini, D. \& Vincenzini, M., 1998. Dynamics of yeast populations during the early stages of natural fermentations for the production of Brunello di Montalcino wines. Food Technol. Biotechnol. 36, 313-318.

Henick-Kling, T., Edinger, W., Daniel, P. \& Monk, P., 1998. Selective effects of sulphur dioxide and yeast starter culture addition on indigenous yeast populations and sensory characteristics of wine. J. App. Microbiol. 84, 865-876.

Hernández-Orte, P., Cersosimo, M., Loscos, N., Cacho, J., Garcia-Moruno, E. \& Ferreira, V., 2008. The development of varietal aroma from non-floral grapes by yeasts of different genera. Food Chem. 107, 1064-1077.

Holm Hansen, E., Nissen, P., Sommer, P., Nielsen, J.C. \& Arneborg, N., 2001. The effect of oxygen on the survival of non-Saccharomyces yeasts during mixed culture fermentations of grape juice with Saccharomyces cerevisiae. J. Appl. Microbiol. 91, 541-547.

Hornsey, I., 2007. The chemistry and biology of winemaking. The Royal Society of Chemistry, Cambridge, UK.

Jolly, N.P., Augustyn, O.P.H. \& Pretorius, I.S., 2003a. The effect of non-Saccharomyces yeasts on fermentation and wine quality. S. Afr. J. Enol. Vitic. 24, 55-62.

Jolly, N.P., Augustyn, O.P.H. \& Pretorius, I.S., 2003b. The use of Candida pulcherrima in combination with Saccharomyces cerevisiae for the production of Chenin blanc wine. S. Afr. J. Enol. Vitic. 24, 63-69.

Jolly, N.P., Varela, C. \& Pretorius, I.S., 2014. Not your ordinary yeast: NonSaccharomyces yeasts in wine production uncovered. FEMS Yeast Res. 14, 215-237.

Kurtzman, C.P., 2011 ( $5^{\text {th }}$ ed). Torulaspora Lindner. In: Kurtzman, C.P., Fell, J.W. \& Boekhout, T. (eds). The yeasts - A taxonomic study. Elsevie Science Publishers B.V, Amsterdam. pp. 867 - 874.

Kurtzman, C.P., Fell, W.F. \& Boekhout, T., 2011 (5 $5^{\text {th }}$ ed). The yeasts, A taxonomic study. Elsevier Science Publishers, Amsterdam.

Lafon-Lafourcade, S., 1983. Wine and brandy. In: Rehm, H.J. \& Reed, G. (eds). Biotechnology: Food and feed production with microorganisms. Verlag Chemie, Weinheim. pp. $82-163$.

Lambrechts, M.G. \& Pretorius, I.S., 2000. Yeast and its importance to wine aroma - A review. S. Afr. J. Enol. Vitic. 21, 97-129.

Lema, C., Garcia-Jares, C., Orriols, I. \& Angulo, L., 1996. Contribution of Saccharomyces and non-Saccharomyces populations to the production of some components of Albariño wine aroma. Am. J. Enol. Vitic. 47, 206-216.

Lerm, E., Engelbrecht, L. \& Du Toit, M., 2010. Malolactic fermentation: The ABC's of MLF. S. Afr. J. Enol. Vitic. 31, 186-212.

Loira, I., Morata, A., Comuzzo, P., Callejo, M.J., González, C., Calderón, F. \& Suárez-Lepe, J.A., 2015. Use of Schizosaccharomyces pombe and Torulaspora delbrueckii strains in mixed and sequential fermentations to improve red wine sensory quality. Food Res. Int. 76, 325-333.

Loureiro, V. \& Malfeito-Ferreira, M., 2003. Spoilage yeasts in the wine industry. Int. J. Food Microbiol. 86, 23-50.

Minnaar, P.P., Ntushelo, N., Ngqumba, Z., Van Breda, V. \& Jolly, N.P., 2015 The effect of Saccharomyces cerevisiae and Torulaspora delbrueckii yeasts on the anthocyanins and flavanols of Cabernet franc and Pinotage wines. S. Afr. J. Enol. Vitic. 36, 50-58.

Moreno, J.J., Millán, C., Ortega, J.M. \& Medina, M., 1991. Analytical differentiation of wine fermentations using pure and mixed yeast cultures. J. Ind. Microbiol. 7, 181-190.
Ngqumba, Z., Ntushelo, N., Jolly, N.P. Ximba, B.J. \& Minnaar, P.P., 2017. Effect of Torulaspora delbrueckii yeast treatment on flavanols and phenolic acids of Chenin blanc wines. S. Afr. J. Enol. Vitic., 38, 192-200.

Ott, R.L. \& Longnecker., M., 2001. An introduction to statistical methods and data analysis. 5th Edition Belmont. California, Duxbury Press.

Padilla, B., Gil., J.V. \& Manzanares, P., 2016. Past and future of nonSaccharomyces yeasts: From spoilage microorganisms to biotechnological tools for improving wine aroma complexity. Front Microbiol. 7, 1-20.

Pretorius, I.S., 2000. Tailoring wine yeast for the third millennium: Novel approaches to the ancient art of winemaking. Yeast 16, 675-729.

Renault, P., Coulon, J., De Revel, G., Barve J-C. \& Bely, M., 2015. Increase of fruity aroma during mixed $T$. delbrueckii/S. cerevisiae wine fermentation is linked to specific ester enhancement. Int. J. Food Microbiol. 207, 40-48.

Renault, P., Coulon, J., Moine, V., Thibon, C. \& Bely, M., 2016. Enhanced 3-sulfanylhexan-1-ol production in sequential mixed fermentation with Torulaspora delbrueckii/Saccharomyces cerevisiae reveals a situation of synergistic interaction between two industrial strains. Front. Microbiol. 7, $1-10$

Renault, P., Miot-Sertier, C., Marullo, P., Hernández-Orte, P., Lagarrigue L., Lonvaud-Funel, A. \& Bely, M., 2009. Genetic characterisation and phenotypic variability in Torulaspora delbrueckii species: Potential applications in the wine industry. Int. J Food Microbiol. 134, 201-210.

Romani, C., Domizio, P., Lencioni, L., Gobbi, M., Comitini, F., Ciani, M. \& Mannazzu, I., 2010. Polysaccharides and glycerol production by non-Saccharomyces wine yeasts in mixed fermentation. Quad. Vitic. Enol. Univ. Torino, 30, 185-189 www.ricercatuscania.it/data/files/romani macrowine 2010.pdf

Romano, P., Fiore, C., Paraggio, M., Caruso, M. \& Capece, A., 2003. Function of yeast species and strains in wine flavour. Int. J. Food Microbiol. $86,169-180$.

Shapiro, S.S. \& Wilk, M.B., 1965. An analysis of variance test for normality (complete samples). Biometrika 52, 591-611.

Taillandier, P., Phong Lai, Q., Julien-Ortiz, A. \& Brandam, C., 2014. Interactions between Torulaspora delbrueckii and Saccharomyces cerevisiae in wine fermentation: Influence of inoculation and nitrogen content. World J. Microbiol. Biotechnol. 30, 1959-1967.

Van Breda, V., Jolly, N. \& Van Wyk, J., 2013. Characterisation of commercial and natural Torulaspora delbrueckii wine yeast strains. Int. J. Food Microbiol. 163, 80-88.

Van Keulen, H., Lindmark, D.G., Zeman, K.E. \& Gerlosky, W., 2003. Yeasts present during spontaneous fermentation of Lake Erie Chardonnay, Pinot Gris and Riesling. Antonie Leeuw. 83, 149-154.

Vaughan-Martini, A. \& Martini, A., 2011 (5 $5^{\text {th }}$ ed). Saccharomyces Meyen ex Reess (1870). In: Kurtzman, C.P., Fell, J.W. \& Boekhout, T. (eds). The yeasts - A taxonomic study. Elsevier Science Publishers B.V, Amsterdam. pp. $733-746$.

Velázquez, R., Zamora, E., Álvarez, M.L., Hernández, L.M. \& Ramirez, M., 2015. Effects of new Torulaspora delbrueckii killer yeasts on the must fermentation kinetics and aroma compounds of white table wine. Front. Microbiol. 6, 1-11.

Wang, C., Mas, A. \& Esteve-Zarzoso, B., 2016. The interaction between Saccharomyces cerevisiae and non-Saccharomyces yeast during alcoholic fermentation is species and strain specific. Front Microbiol. 7, 1- 11. 